\title{
Contribuições de Francisco Varela ao Estudo da Aprendizagem Inventiva em Sala de Aula
}

\section{Francisco Varela's Contributions to the Study of Inventive Learning in Classroom}

Resumo: Este artigo se propõe a fazer um percurso pela obra de Francisco Varela e colaboradores (VARELA; THOMPSON; RORSCH, 2003, DEPRAZ; VARELA; VERMERSCH, 2003) buscando mapear suas contribuições em relação ao funcionamento e a aprendizagem da atenção. As autoras discutem as vicissitudes das aprendizagens recognitiva e inventiva e os tipos de atenção que acompanham essas concepções sobre o aprender. Exploram o conceito vareliano de breakdown para discutir as práticas de sala de aula não mais marcadas pela atenção focalizada - característica do modo de atencional da contemporaneidade - mas uma atenção consciente, marcada pelo continuum esperar-esticar, fixar-romper, atender-desatender.

Palavras-chave: Aprendizagem. Sala de aula. Atenção recognitiva/inventiva.

Abstract: This paper aims to present contributions concerning Francisco Varela's and colaborator's (VARELA; THOMPSON; RORSCH, 2003, DEPRAZ; VARELA; VERMERS$\mathrm{CH}, 2003$ ) thinking about the functioning and learning of attention. The authors discuss the ways apprenticeship can be either recognitive or inventive and the types of attention that accompany these conceptions of learning. They explore the varelian concept of breakdown in order to discuss classroom practices that do not limit attention exclusively to focus - which are so common in modern times - but cultivate a conscious attention, following the continuum of being stretched and of waiting; fixed and suspended; attentive - non-attentive.

Keywords: Learning. Classroom. Recognitive/inventive attention.

\author{
Regina Orgler Sordi \\ Universidade Federal do Rio Grande do Sul \\ Maria Helena De-Nardin \\ Universidade Federal do Rio Grande do Sul
}

SORDI, Regina Orgler: DE-NARDIN, Maria Helena. Contribuições de Francisco Varela ao Estudo da Aprendizagem Inventiva em Sala de Aula. Informática na Educação: teoria \& prática, Porto Alegre, v. 12, n. 2, p. 82-92, jul./dez. 2009.

\section{I ntrodução}

P artimos da hipótese de que é possível mobilizar distintos regimes atencionais para viabilizar diversas experiências de aprendizagem. Neste sentido, compartilhamos com a contribuição de Kastrup (1999), para quem a cognição pode se expressar através de duas formas: recognitiva e inventiva. Segundo a autora, será o aspecto inventivo da cognição, que até então vinha se apresentando com um caráter bastante restrito no âmbito da psicologia cognitiva, que possibilitará pensar um sujeito capaz de inventar a si e ao mundo. Nesse processo, é a atuação do sujeito que possibilita novas formas de conhecer, de pensar e de produzir outras configurações de mundo. Recognição e invenção ocuparão lugares distintos, mas complementares no processo da cognição e é através de seus desdobramentos que fomos buscar suporte para poder seguir pensando os diferentes modos de atenção convocados em cada experiência.

De um lado, temos as experiências de recognição que permeiam nosso cotidiano e nos permitem o reconhecimento dos objetos e de operações entre os mesmos de modo que possamos ter um bom desempenho diante das 
situações com as quais nos deparamos. São elas que nos dão condições de solucionamos nossos problemas mais imediatos. Por outro lado, a cognição não se esgota na repetição e na solução do problema, mas se potencializa na capacidade humana de problematizar e na sua atividade inventiva que elimina o determinismo do objeto ou do ambiente.

Originária do latim invenire, a palavra invenção significa compor com restos arqueológicos (KASTRUP, 1999). Na ação de compor, está implicada uma certa prática, uma experimentação, um trabalho com restos que num momento determinado - o momento da invenção - , quando da remoção das camadas, revela aquilo que se encontrava oculto. Esta prática conduz a um resultado imprevisível marcado pela produção tanto do sujeito quanto do mundo. Produção que se dá num momento de encontro com o inesperado, quando a invenção, por seu caráter de problematização, opera com sua tendência crítica. Em uma experiência dessa ordem, sensibilidade, memória e atenção percorrem caminhos distintos, produzindo um estranhamento que ultrapassa o reconhecimento e força a aprendizagem que começa nesse exato momento (KASTRUP, 1999).

Para fundamentar a hipótese sobre a mobilização de distintos regimes atencionais para as experiências de aprendizagem, buscamos as contribuições de Arvidson (1998, 2000), James (1952) e, principalmente, de Varela e seus colaboradores.

Nos trabalhos destes últimos, encontramonos com o conceito de breakdown que foi utilizado como norteador da nossa pesquisa intitulada Um Estudo Sobre as Formas de Atenção em Sala de Aula e Suas Relações com a Aprendizagem (DE-NARDIN, 2007), cujas considerações serão retomadas neste artigo.

Varela (2003) utiliza o termo para referir-se a uma espécie de abalo ou colapso, ou ainda rachadura na continuidade cognitiva, que é da ordem do imprevisível. Esse movimento, segundo o autor, potencializa o nascimento do novo, pois embora pareça paradoxal, o colapso não rompe o fluir da conduta, mas o assegura, tendo em vista que remete o sujeito a experimentar algo do campo pré-subjetivo, ou seja, algo que tem a ver com a dinâmica entre elementos da rede neuronal. O que acontece no momento do colapso, não é um rompimento, mas um diálogo entre uma situação específica vivida e a capacidade do sujeito para exercer ações apropriadas em determinadas circunstâncias, efeito da maneira pela qual corporifica uma série de atuações recorrentes, constituídas sócio-historicamente.

Varela (2003) afirma que cada sujeito constrói durante sua vida um repertório de comportamentos básicos que constituem o que ele denominou de prontidão-para-a-ação no presente, responsável pelas condições de agir adequadamente diante de situações específicas. Essas prontidões são construídas socialmente e dizem respeito a corporificações de ações vividas em diferentes momentos de nossa atuação no e com o mundo. Quando o sujeito se encontra diante de uma nova situação, sofre pequenos colapsos ou breakdowns, quando então mergulha em seu próprio plano de construções, resultando em novas correlações entre o sistema sensorial e o motor - elaboradas pelo sistema nervoso - que produzirão uma nova ação. Essas novas correlações são criadas pelo sujeito e por sua maneira particular de se deixar afetar pelos estímulos do mundo físico, que nada mais são do que disparadores de transformações que, em última instância, são determinadas pela estrutura do sistema nervoso.

Deixar-se afetar consiste em um aspecto importante da nossa atenção, cujo real - aquilo que ela seleciona do ambiente - encontra sua contraparte na distração. A distração, como aqui é entendida, seria o fôlego da atenção: um momento de recuo necessário para que se possa viver uma experiência de si, que tem sido menosprezada pelos modos de absorção rápida produzidos pelo mundo midiático. A distração abre espaço para o que não é imediato, para o que permite o movimento do sujeito, sua experiência de duração. A distração, que é um dos aspectos da concentração, mostrase, então, como imanência da criação. Quando um breakdown acontece, o sujeito pode experimentar uma abertura estética, deixando o mundo conversar consigo. O breakdown vem acompanhado por dois movimentos: de focalização e de distração. De distração, porque ele força a sair do agora (do reconhecimento) e a transitar em outros espaços-tempos, cuja potência está no por vir. Estas forças se acoplam e produzem ao mesmo tempo subjetivação e objetivação. Dá-se a invenção, que é pessoal, pois se trata de um inventar a si e ao mundo. 


\section{Uma Revisão Sobre os Estudos Sobre a Atenção: da Psicologia às Ciências Cognitivas}

Traçando um panorama geral sobre o desenvolvimento dos estudos sobre a atenção, Arvidson $(1998,2000)$ mostra que muitos pesquisadores situam suas investigações sobre a atenção no campo da consciência, onde o protagonista das pesquisas fica sendo nossa capacidade de focalização, isto é, de ignorar ou retirar do foco algum objeto para situá-lo em outro. Então, o sucesso de uma atenção focalizada determina-se pela liberdade do sujeito de ignorar os estímulos irrelevantes para a execução de determinadas tarefas. A similaridade entre atenção e intenção tem dado o tom à maioria das pesquisas. Desde esta perspectiva, a atenção é entendida apenas como uma atenção seletiva, caracterizada por uma certa capacidade de sustentação. Tudo o que está fora desta capacidade, fica situado no âmbito da desatenção. Sendo assim, há uma tendência a definir o que está consciente como atenção e o que não está consciente como desatenção. Esta visão acabou priorizando a concepção de atenção como um processo único e homogêneo, reduzido-a ao ato conhecido como ato de prestar atenção. Esta mesma visão sustenta a maioria dos debates em torno do Transtorno de Déficit de Atenção com Hiperatividade (TDAH).

Tal entendimento sobre a atenção vem sendo contestado por um bom número de pesquisadores, principalmente, nas últimas décadas. As pesquisas que vêm sendo desenvolvidas têm promovido uma retomada aos estudos da Filosofia e da Psicologia da segunda metade do século XIX e vêm indicando que o conceito de atenção não pode ficar reduzido ao ato de (em)prestar atenção. As novas abordagens, na contra-mão das teorias behavioristas hegemônicas, vêm sugerindo um caráter volátil e heterogêneo da atenção, contrariando as afirmações referentes à sua compreensão enquanto atividade autônoma e voluntária e conduzindo a uma ruptura nas noções de similaridade entre consciência e atenção vigentes durante o século $X X$.

James (1952), Bergson (1999, 2005) e Freud (1969) são autores para quem o conceito de atenção tem servido de ponto de contato para os novos estudos que, no cenário atual das ciências cognitivas, vêm ganhando um novo destaque.
Embora Willian James defendesse a atenção como uma atividade voluntária e seletiva, orientada pelo interesse e aplicada à ação, segundo Crary (1999) e Arvidson (2000), ele foi um dos primeiros a reconhecer seu estado involuntário e fluido, destacando uma certa divisão do campo da consciência em central (um foco) e não central (a margem). Todavia, o que mais Ihe interessou, segundo Arvidson (2000, p.15) foi o "[ . . . ] fluxo temporal e o fluxo perceptivo do campo fenomenal [ . . . ]", de forma que a ênfase ficou situada no contexto da teoria do fluxo da consciência, tendo em vista a idéia de movimento, proposta por James. Ao referir-se à atenção voluntária, James (1952) afirma que não há uma atenção voluntária que se sustente por mais do que alguns segundos. O que é chamado de atenção voluntária é, na verdade, a repetição de um esforço sucessivo em trazer o foco de volta para a mente. A atenção, com sua tendência a escapar a todo o momento, opera por puxões, por sacudidelas e, para se manter no foco, ela demanda um exercício constante de retomadas. Este movimento a caracteriza como uma operação volátil. Trata-se de uma oscilação natural, independente do esforço da vontade consciente.

Uma das contribuições de Bergson (1999), que aqui nos interessa, diz respeito ao seu conceito de duração. Este conceito aponta para a existência de uma atenção que não se confunde com aquela envolvida nas atividades práticas da vida cotidiana, mas que se caracteriza pela experiência de um mergulho no já vivido e que permite ao sujeito uma volta à experiência, impregnado de lembranças que atuam no momento atual, possibilitando-lhe uma vivência de conexão entre passado e presente, desde onde se torna possível a invenção. Então a atenção à duração pressupõe a distração, o que implica numa certa errância. É esta capacidade que interessa aqui, pois situa a atenção em um patamar distinto do ato de focalização.

Embora não se pretenda fazer um exame detalhado das contribuições de Freud (1914), é importante fazer referência ao seu conceito de atenção flutuante que vem ao encontro do estudo da atenção em sua complexidade, apontando a necessidade de rever as idéias de atenção como um processo homogêneo. O termo atenção flutuante foi cunhado por Freud (1969, p.149-150) para falar de uma atenção 
que não “[. . . ] quer se fixar em nada em particular [ . . . ]". É a atenção exercida pelo analista no espaço clínico e "[ . . . ] consiste simplesmente em não dirigir o foco para algo específico e manter a atenção uniformemente suspensa em face de tudo o que se escuta [ . . . ]". Praticando essa suspensão, a atenção se mantém aberta, sem focalização específica, o que torna possível sintonizar a escuta com as associações inconscientes trazidas pelo paciente. Para Freud, uma atenção seletiva, que se caracteriza por ser voluntária, consciente e focalizada, poderia se tornar perigosa à medida que "[ . . . ] começa a selecionar o material que Ihe é apresentado; um ponto fixar-se-á em sua mente com clareza particular e algum outro será, correspondentemente, negligenciado, e, ao fazer essa seleção, estará seguindo suas expectativas ou inclinações [ . . . ]" (FREUD, 1969, p. 149-150). Esta postura traria grandes obstáculos às descobertas.

Inspirados nesses e em outros autores, grupos de pesquisadores contemporâneos, dentre os quais se encontram Arvidson (1998, 2000), Depraz, e Vermersch (1999, 2003), vêm postulando que o ato de prestar atenção, identificado com a capacidade de focalização, é apenas um dos momentos de um processo que se revela complexo, no qual estão incluídas diferentes modulações. Trata-se da inclusão, no campo de estudo, de outras dimensões da consciência que normalmente são tomados como não-consciência ou inconsciência. O estudo da atenção vem revelando, não só o aspecto de intencionalidade da consciência, mas também sua dimensão de variação e modulação.

A suposta correspondência entre atenção e consciência, realizada por uma série de pesquisadores, é considerada por Arvidson (1998, 2000) um tanto restrita e capaz de produzir alguns equívocos. Um deles revela-se pela concepção da consciência como unidimensional. Apoiando-se no trabalho de Aron Gurwitsch, para apresentar uma alternativa aos postulados de Galen Strawson que propõe que a consciência sai de férias, Arvidson (2000) é enfático em afirmar seu caráter contínuo. Para o autor, a consciência está organizada em um modelo que não se reduz a um foco atencional, mas, que ao ser adotada uma dimensão ampliada, comporta um campo tri-dimensional, constituído por tema, campo temático e margem. Conforme sugere Arvidson (2000), estamos constantemente experimentando es- tas três dimensões, deslizando entre elas num movimento de ir e vir, cuja organização individual é específica. O tema corresponde ao foco da atenção, é para onde está dirigido e investido o interesse do sujeito. O campo temático diz respeito a tudo que tem alguma relação de relevância e coerência com o tema, revelando um determinado contexto desde onde vivemos nossas experiências diárias. A margem, por sua vez, abrange tudo o que se mostra como irrelevante para o tema, mas que pode surgir de algum lugar (um barulho inesperado, por exemplo) e transformar-se, assim como o campo-temático, em foco principal.

A afirmação de que transitamos de uma dimensão a outra sugere um modo como estamos sempre conscientes. Isto amplia o conceito de consciência, permitindo pensá-la como portadora de um caráter de continuidade temporal e atencional. Portanto, no que diz respeito aos deslocamentos atencionais, ela não nos permite sair de férias, pois nunca está radicalmente desconectada. Ainda que a atenção não esteja incidindo sobre um foco específico, nossa consciência não nos abandona. A consciência, diz Arvidson (2000), escorrega, diminui e se transforma, mas não necessariamente desaparece. O que nos permite admitir que ela também experimenta uma certa errância. Fica, então, sugerida uma concepção não-egóica da consciência.

Ao estabelecer a tri-dimensionalidade da consciência, o autor propõe uma tipologia da atenção a partir dos deslocamentos de intensidade e de direção entre um e outro, bem como de transformações diversas que pode sofrer o tema a partir destes deslocamentos. Argumenta que há um significante atencional e temporal contínuo na consciência. O deslizamento da consciência entre as distintas dimensões sugeridas por Arvidson (2000) propõe um modo de funcionamento da consciência na vida desperta. Os deslocamentos da atenção em consciência são essencialmente transformações de trocas de direção e de dimensão daquilo que se mostra no campo da percepção. Isto sugere que não há apenas um modo de atenção, mas modos que se diferenciam um do outro em sua forma de transitar entre tema (foco), campo-temático (contexto) e margem, além da capacidade de admitir transformações de uma dimensão em outra, como por exemplo, algo que está à margem da consciência pode tornar-se seu foco. 
Para este artigo, interessa avançar na consideração do que Arvidson (2000) apresenta como essencial, e que Bergson (1999) também revela nos seus estudos filosóficos: o caráter fluido e heterogêneo da atenção, no qual Depraz, Varela e Vermersch $(1999,2003)$ também estão interessados. Estes três autores trazem, então, uma contribuição significativa para os estudos da atenção: eles propõem o desenvolvimento e estruturação de uma metodologia para o ato de tornar-se consciente, sugerindo a possibilidade de uma atitude cognitiva que implica o aprendizado de um modo de atenção qualitativamente diferente do modo focalizado.

$\mathrm{O}$ ato de tornar-se consciente foi estudado em distintas práticas, dentre as quais, a meditação budista, a entrevista de explicitação (ou introspecção guiada), a reza do coração, a visão estereoscópica, a prática clínica psicanalítica, a sessão de escrita, e até mesmo o aprendizado da Filosofia. Pela prática metodológica proposta pelos autores, é possível chegar a tornar-se consciente, que é o ato de tornar claro para a consciência algo que nos habitava de modo confuso, opaco, afectivo. Os autores explicam que tais propostas não se esgotam enquanto prática de pesquisa, pois repetidas vivências dessas experiências tendem a qualificar o modo de estar atento dos sujeitos praticantes, podendo assumir um caráter de prática de transformação de si e de relação consigo. Há na descrição do ato um caráter processual que é enfatizado pelo interesse dos pesquisadores em conhecer a experiência humana enquanto ela está em atividade, em movimento, ressaltando sua mutabilidade e fluidez. Dentre a diversidade de vivências possíveis, a sala de aula, ao cultivar experiências de problematização, pode se constituir num espaço singular de aprendizagem da atenção.

Para compreender o processo de aprendizagem do ato de tornar-se consciente, é preciso conhecer a metodologia proposta a partir do entrelaçamento dos três gestos ou atos que compõem a époché, complementada por evidências intuitivas. Partindo da époché - método de redução fenomenológica formulado por Husserl -, Depraz, Varela e Vermersch (1999, 2003) sugerem uma fenomenologia renovada, incorporando observações da Psicologia e das práticas contemplativas, das quais se baseiam para investigar a experiência humana em ato e não somente os conteúdos de tal experiên- cia. A articulação da dupla - époché/intuição - constitui o que os autores consideram o ciclo básico da operação.

A estrutura geral da époché desdobra-se em três gestos: suspensão, redireção e deixar vir. A suspensão é o início da époché, sendo alusiva ao momento em que o fluxo natural de nossa atitude cognitiva de reconhecimento das coisas é interrompido. Ela pode ser desencadeada por um acontecimento, por motivações intersubjetivas ou individuais, destacando-se a surpresa estética. A experiência estética é pré-conceitual e pré-simbólica e portanto não obedece a qualquer finalidade. Ela apenas acontece num momento único. É indescritível e só se torna possível pela capacidade humana de descentrar-se, intuir, apreender o sensível, fusionar-se. A experiência estética do conhecimento se conecta com a capacidade de produzir efeitos que são da ordem do imprevisível e, portanto, impossíveis de serem antecipados. São momentos, por excelência, de descontinuidade, de intervalos, de silêncio que dão espaço à autoria, como as pausas que dão sonoridade à música e sentido à fala. Por isto a suspensão pode ser entendida tanto como uma interrupção do fluxo cognitivo quanto como uma suspensão no tempo.

Os outros dois atos da époché, redireção da atenção e deixar vir, são complementares e pressupõem a possibilidade de manter a suspensão. Esta espera é considerada o maior obstáculo para que o ato de tornar-se consciente se cumpra, pois é preciso que a atenção seja sustentada para que redireção e deixar vir aconteçam. Elas são importantes para o problema da atenção, pois correspondem a duas mudanças fundamentais da atividade cognitiva. Com o ato da suspensão, a atenção é redirecionada do exterior - para onde ela naturalmente está voltada - para o interior. Ao distanciar-se daquilo que está dado diretamente à percepção, a atenção a si torna-se possível, pois a tendência recognitiva está momentaneamente suspensa. Neste momento, não há nada a fazer, apenas é preciso parar e prestar atenção ao que está por vir. Como o ato ocorre sob suspensão, a relação consigo que o sujeito experimenta não dá lugar a preocupações, lembranças ou pensamentos. Ela vai se ocupar com o movimento seguinte - o terceiro gesto do ciclo - que é deixar algo vir, deixar algo ser revelado. Embora aparente uma certa passividade, o deixar vir exige um trabalho de espera 
sem conhecimento do conteúdo, promovendo um encontro. Experiências no campo da arte são ilustrativas de tal ato, pois se trata de um movimento que se desloca de uma atividade de pesquisa, para uma atividade de acolhimento. Todavia, trata-se de um encontro com algo que vem de si, pois, nesse momento, a atenção está voltada para si, numa atitude de escuta.

Por fim, a emergência intuitiva finaliza o processo. Ela se revela clara e explícita, como fruto de uma experiência individual com enraizamento no coletivo, mostrando-se como um modo especial de conhecer. Cabe ressaltar, que os três gestos não seguem uma ordem sequencial-linear. Eles fazem parte de um ciclo, entrelaçam-se e movimentam-se circular e correlativamente, de forma que cada um deles, ao mesmo tempo em que ultrapassa o anterior, também o conserva.

Esse movimento transforma a qualidade da atenção que se transmuda de uma atenção focalizada para uma atenção concentrada e aberta donde é permitido distrair-se para encontrar-se com aquilo que se revela. Em tal estado de concentração, que nos possibilita o encontro com elementos do plano pré-reflexivo, não há focalização e por isto não se trata de um modo de atenção envolvido nas atividades diárias.

Na medida em que as modalidades de ensino estão basicamente fundamentadas em processos de recognição que marcam tais atividades, o ato de prestar atenção, cujo conceito atual limita-se ao processo de focalização, está associado à recognição como uma das suas condições indispensáveis. Entretanto, conforme os estudos vêm mostrando, o prestar atenção é apenas um momento de um processo bem mais complexo, que inclui modulações da cognição e da própria intencionalidade da consciência.

Aprofundando-se nas experiências de práticas budistas, Varela, Thompson e Rosch (2003) confirmam o funcionamento da atenção como uma constelação de experiências e práticas. 0 objetivo das práticas budistas é levar a pessoa a tornar-se atenta a si, ou seja, experienciar o que a mente está fazendo, enquanto ela o faz. Para entender o significado destas palavras é preciso lembrar que diariamente vivenciamos situações em que passamos pela experiência sem a plena consciência de tê-la vivido. Quantas vezes, nos trajetos que percorremos, sequer lembramos qual o caminho percorrido, se os semáforos pelos quais passamos estavam dando condições de passagem ou não? Este é um exemplo simples de que é normal estarmos em estado de não-atenção, ou seja, nosso corpo e nossa mente não estão estreitamente coordenados. Na tradição budista, significa que não estamos presentes na experiência.

Quando a atenção está dispersa, transitamos de um foco a outro na mais absoluta ausência. Experimentamos o efeito zapping, que consiste em passar rapidamente de uma situação a outra, sem apreender o sentido de cada experiência. A dissociação entre mentecorpo, consciência-experiência é resultado dos nossos modos de experimentar a vida e o tempo. Seguir a mente, como propõe o budismo, requer o abandono de hábitos de não-atenção do tipo dos descritos acima. Isto permite pensar na possibilidade de aprendizagem da atenção, uma aprendizagem que tem mais a ver com desaprender, propondo um movimento da atenção que rompe com um estado de nãoestar atentamente envolvido com o que está acontecendo.

O princípio da prática da atenção no modelo budista “[ . . . ] é o cultivo da atenção por meio de uma concentração relaxada no surgimento de cada momento da experiência [ . . . ]" (VARELA, 2003 p. 91). Varela utiliza o termo concentração relaxada indicando a possibilidade de distrair-se no momento mesmo da focalização e seguir a mente onde ela for. Ela se distrai do aqui e do agora, do foco perceptivo e segue seu curso, sem perder a consciência ou sem perder a relação que une a pessoa que experiencia e o objeto experienciado.

O exercício da concentração relaxada possibilita a aprendizagem de segurar em contemplação o objeto da atenção. É o oposto do que se experimenta diante do espetáculo do mundo que se percebe, quando a experiência se revela como um modo de estar focalizado.

Prestar atenção à aula requer uma capacidade de focalização, embora já possamos afirmar que não é suficiente para uma aprendizagem inventiva. Inventar exige um movimento que nos obriga a sair do foco. Reconhecer, ao contrário, requer a experiência de permanência no foco.

De acordo com Kastrup (2004), pode haver focalização sem concentração da mesma forma que pode haver concentração sem focalização. Toda vez que somos chamados a prestar atenção, seja para tarefas escolares ou não, 
subjacente ao apelo está um conceito que faz referência a um movimento de detenção, o que não implica, necessariamente, em capacidade de concentração. Detenção tem relação com fixação do foco, enquanto concentração tem a ver com uma certa abertura que, em seguida, revela-se como distração. Na escola, no trabaIho, em frente ao computador ou à televisão ou em outras tarefas diárias, nossa atuação normalmente é de uma atenção focalizada, pois precisamos tratar de reconhecer o que se passa para poder executar bem as tarefas.

$\mathrm{Na}$ perspectiva recognitiva de aprendizagem, não está implicada necessariamente uma concentração, porque a concentração, como referida neste estudo, supõe a possibilidade de ir além da capacidade de executar tarefas; supõe uma possibilidade inventiva e, portanto, uma cognição enquanto proponente de problemas. Neste caso, a concentração, ao contrário do que normalmente se pensa, precisa recorrer à possibilidade de se distrair, sendo este experimentado como um colapso, numa rachadura (VARELA, 2003), numa suspensão (DEPRAZ; VARELA; VERMERSCH, 2003), ou ainda um momento de descontinuidade (BERGSON, 2005). Dá-se um movimento em que o sujeito pode e necessita, se falamos em invenção, transitar entre atenção e desatenção. É nesse estar entre que ele se encontra com a possibilidade de escavar, de fazer um trabalho tateante. $O$ encontro se dá entre algo que nos habita, mas que não está sob o controle do eu, tampouco é da ordem do conhecimento. Trata-se de uma experimentação nova que, ao sofrer uma ruptura na continuidade, escapa ao instante presente, ao momento da focalização, mas mantém um elo de ligação que reconduz o sujeito e possibilita que o problema seja inventado.

No momento da concentração, haverá uma inibição do foco e uma renúncia a perseguir o resultado útil da percepção, acontecendo um novo circuito que permite ao sujeito uma relação consigo e cujo progresso da atenção terá por efeito criar o novo. Há um intervalo, mas o sujeito se mantém ligado com a noção anterior; ao passo que na focalização, ao ser rompido o foco, não se mantém qualquer conexão com o que vinha atendendo anteriormente. As características fundamentais da concentração são a continuidade e a heterogeneidade, pois falamos de experiências que conservam atual e atuante o passado no presente, ao mesmo tempo em que introduzem distinções, produzindo o novo.

A partir das questões suscitadas pelos estudos sobre a atenção, caberia, então, pensar num papel criativo de uma atenção distraída e na relação entre tempo e subjetividade, visto que os modos de experimentação dos ritmos de temporalidade são intrínsecos à nossa constituição subjetiva. É desde a possibilidade de distrair-se que o sujeito se encontra diante de experiências que lhe permitem problematizar. Ao deixar de habitar o instante do reconhecimento, o sujeito pode habitar outras temporalidades, o que Ihe permitirá descobrir novas verdades no tempo que parece perder ao distrair-se. As verdades da inteligência, na perspectiva recognitiva, só possuem uma verdade lógica, uma verdade possível. Esta verdade recusa-se a perder tempo. Para uma competente gestão do presente, a estratégia é viver o agora, o que implica em um aproveitamento eficaz do tempo. Neste contexto, é proibido distrair-se.

Assim, de um lado lidamos com a maneira como a atenção é problematizada hoje, enquanto um elemento necessário para o reconhecimento da informação; de outro, deparamo-nos com os estudos da consciência em que a atenção que emerge como um estado possível e necessário para a invenção é uma atenção capaz de transitar entre estados de atenção focalizada e estados de atenção distraída. Nesta última maneira, encontramos atenção como uma constelação de experiências e práticas, muito mais que uma questão de fixação, de olhar ou de sujeito como espectador.

\section{Entre a Atenção Recognitiva e a Atenção I nventiva, Novas Formas de Aprender}

Tal trânsito entre a atenção recognitiva e a atenção inventiva revela a heterogeneidade da atenção e a complexidade do tema quando abordado desde uma perspectiva escolar. Se entendermos a cognição em sua dimensão criadora, então é preciso escutar as distrações dos alunos e não apenas rechaçá-las como empecilhos para a aprendizagem. Também cabe ao/à professor/a uma certa atenção distraída, pois é esta que Ihe dará condições de acolher o inesperado, o que está por vir. Ao fazê-lo, o/a docente põe em jogo, principalmente, a própria capacidade criadora e a dos alunos, 
quando, então, pode instalar-se a pergunta. É a tensão entre focalização e distração que sustenta um espaço de ensino-aprendizagem onde a invenção se torna possível. Então, para que seja possível a invenção no espaço escolar, pode e deve haver um movimento circular de ruptura, redireção e de deixar vir. A focalização exclusiva presta-se apenas à reprodução do mesmo.

Se considerarmos a afirmação de James (1952) de que a atenção voluntária não se sustenta por muito tempo e por isso ela opera por sacudidelas para manter-se no foco, então, podemos afirmar que ela se sustenta regulando, eficazmente, suas descontinuidades, seu ir e vir. Eficácia que se constrói pelas vias da aprendizagem, tanto quanto nossa forma de ser e de viver, quanto nossas atuações e interações.

Os muitos exemplos de práticas escolhidos por Depraz, Varela e Vermersch (2003), para estudar o ato de tornar-se consciente, revelam-se práticas de aprendizagem da atenção que vão resultar em práticas de presença de si. Tais pesquisas nos levam a pensar que a sala de aula, assim como outros espaços, pode se revelar propícia para aprendizagens semelhantes. Para a pergunta, Seria a atenção, com relação à aprendizagem, efeito ou causa?, poder-se-ia responder: num sentido é causa, uma vez que seu papel é dirigir a escolha, selecionar o foco e manter o sujeito numa relação com o objeto. Mas, em outro sentido, é efeito, quando se torna uma atividade de encontro entre experiências pré-egóicas e a experiência atual do sujeito, o que a constitui enquanto atenção distraída. Se não for assim, a possibilidade de distrair-se desaparece e a invenção rompe seu fluxo.

A aprendizagem é a característica marcante das diferentes práticas do ato de tornar-se consciente estudadas por Depraz, Varela e Vermersch (2003) e a lógica temporal dessa aprendizagem não é linear. Ela não se encerra quando finda a atividade, ela segue produzindo seu efeito depois do trabalho, quando se pode sentar e pensar sobre o aprendido, ou até mesmo falar sobre a experiência. Este ato é um ato de re-experimentação da vivência, quando acontece o ressurgimento da experiência vivida. Não se trata apenas de uma narrativa enquanto produto, mas de uma reexperimentação que requer suspensão. Então, um dos pontos altos dessa aprendizagem vem depois da prática.
O tempo da aprendizagem é marcado por um momento de treino e por um momento dos pós-efeitos da sessão que preparam o sujeito para a sessão seguinte. Sendo assim, após o tempo da surpresa e da novidade com o qual se encontra o sujeito no exercício da époché, há o tempo de tornar tal exercício um processo sedimentado, que, embora implique num passo a passo, não é seqüencial, tampouco quantificável, pressupondo repetição e variação. Nesse processo, em que um momento está engajado no outro, incluem-se momentos mais difíceis, que exigem um esforço maior, denominados rio acima (upstream) e momentos mais fáceis, denominados rio abaixo (downstream). Ambos dão ao processo um determinado ritmo, cujo mecanismo é circular.

A especificidade do treino do ato de tornar-se consciente está no fato de que se trata de um aprender fazendo, atuando. Sendo assim, é preciso assinalar que se constitui numa aprendizagem por cultivo, não num trabalho mecânico. Num certo sentido, a prática de experimentação do circuito da atenção (suspensão, redireção e deixar-vir) é uma prática treinada por se assemelhar ao aprendizado de uma habilidade, exigindo um trabalho de longo prazo e de muita persistência. Mas ela não se reduz a isto, pois se refere, acima de tudo, ao cultivo consciente de uma habilidade capaz de modificar uma atitude natural de reconhecimento, tornando-a uma atitude de suspensão e redireção. Envolve, portanto, uma mudança de atitude na relação do sujeito com o mundo. Com a prática constante, o processo da époché vai se estabilizando gradativamente, o esforço requerido para alcançá-lo vai diminuindo e a atenção a si tornando-se espontânea. Os autores comparam tal aprendizagem com a aprendizagem da música, que não envolve apenas tocar, reger ou compor, mas também o desenvolvimento de uma maior sensibilidade em ouvir a música, deixando-se afetar por ela. Ao se deixar afetar, o sujeito transforma-se e vivencia algo em uma dimensão que não é recognitiva, experimentando uma certa desaceleração do tempo, quando o silêncio de poucos segundos pode parecer eterno. Efetivamente, é uma experiência subjetiva intensa e longa, de natureza intuitiva, muito diversa das experiências habituais de funcionamento cognitivo. Durante sua aprendizagem, a arte em geral, como a música, mobiliza e desenvolve uma atitude atencional que se revela concen- 
trada e aberta, envolvendo, além da habilidade técnica requerida, uma aprendizagem da sensibilidade, ou seja, uma aprendizagem de um modo de atender especial, pois possibilita ao sujeito acolher os efeitos sobre si, deixando-se afetar. Em certas atividades humanas, vestígios de uma dimensão estética aparecem claramente, como é o caso dos mitos, da arte em todas as suas manifestações, dos acontecimentos festivos e de todos aqueles que acolhem o surgimento da surpresa e da novidade. Nesses momentos, não há nada para compreender, há uma abertura para o inédito. É, então, sempre uma questão de instantes, de momentos fugazes, de imprevisibilidade que têm a capacidade de fascinar.

Na sala de aula, esse fascínio pode ocupar um lugar, contanto que se convoquem as experiências estéticas possíveis no encontro com a História, com a Geografia, com a Biologia, com a Matemática e a escrita; contanto que se aprenda a dar lugar àquilo que surge desse encontro.

Diferente do que acontece nas práticas de époché, na escola, via de regra, a experiência de suspensão do ato recognitivo é logo apontada como elemento que interfere negativamente na aprendizagem. Se essa suspensão puder ser acolhida, caberá ao professor, ajudar o aluno a perseguir o sentido daquilo que vem, muitas vezes, através de sua fala, aparentemente desconectado ao tema em foco. Caberia ao professor acolher a perturbação e abrir um espaço para que a surpresa da novidade sedimente um novo conhecimento. É a regularidade do cultivo desta prática o que possibilita a constituição de uma atitude atencional ao mesmo tempo concentrada e aberta, necessária no momento da invenção.

Ao pensar a possibilidade da aprendizagem da atenção na sala de aula, não se pretende propor uma nova teoria da aprendizagem. Pensa-se na existência de situações diversas que possibilitem experiências concretas que, através das práticas escolares diárias, possam cultivar um modo de atenção que inclua a possibilidade de problematizar.

Quando nos propusemos a pesquisar as formas de atenção na sala de aula, fizemos uma aposta na possibilidade de que neste espaço acontecessem experiências capazes de ativar um modo de atenção a si, possibilitando a invenção. Partindo desta hipótese, fomos em busca dessas experiências e as condições de possibilidade construídas para que tais fenômenos pudessem se desencadear. Por acreditar que somente uma atenção dessa qualidade é capaz de criar novos problemas, tornava-se necessário localizar estes momentos e o que se passava ali para, então, poder pensar práticas escolares possibilitadoras de uma aprendizagem da atenção inventiva.

Em dois artigos publicados anteriormente (DE-NARDIN; SORDI, 2007, 2009) propusemo-nos a detalhar a pesquisa, sua metodologia e os estudos advindos dela. Realizada com turmas de primeira série do ensino fundamental resultou em uma série de registros sistemáticos das relações aluno-professor-objeto de conhecimento e das modulações da atenção resultantes desse processo.

Neste percurso empreendido durante dois anos, o breakdown configurou-se como um conceito válido para que se pudessem localizar os momentos de ruptura com o foco atencional porque, ao analisá-los, foi possível compreender os fluxos de atenção experienciados pelas crianças, algumas vezes considerados como falta de atenção; outras, como um dispositivo para pensar. O conceito teve igual importância para a análise daquilo que se passou com as professoras ao se depararem com o breakdown infantil. A busca por aquilo que se passou foi revelador para este trabalho.

Como nas práticas da époché propostas por Depraz, Varela e Vermersch (1999, 2003), percebeu-se durante a pesquisa que é preciso criar, na sala de aula, espaços para um regime atencional que possa se alternar entre fixar e segurar algo em contemplação, entre tensão e distensão, entre focalização e distração. Conforme nos mostra o método, o mecanismo para assegurar essa aprendizagem deve estar fundamentado numa experiência continuada, aplicada e disciplinada; e, no caso da sala de aula, orientado por alguém que se deixe afetar com alegria e humor pelas surpresas e pelo desconhecido que pode vir.

Percebemos que quando os alunos podem experimentar o acolhimento do breakdown, uma experiência de comunicação dialógica interacional ${ }^{1}$, momentos estéticos e de produção

10 termo experiência escolar dialógica faz referência a práticas de interlocução onde duas pessoas se abeiram da mesma realidade com o intuito de se acercarem o mais possível de um sentido compartilhado. O diálogo sempre envolve um dos interlocutores tanto quanto o outro. Cada interlocutor fala 
de sentido para o que se diz e faz, práticas coletivas de pensar sobre o pensamento e um trabalho permanente de construção-reconstrução os efeitos são de invenção. Tais experiências, ao se tornarem freqüentes na sala de aula, podem possibilitar o exercício de uma certa hegemonia da consciência sobre os apelos sensórios. Observamos, neste caso, não mais a dispersão que é característica do modo de atencional da contemporaneidade, pois exige do sujeito uma mudança constante do foco-, mas uma atenção consciente, marcada pelo continuum esperar-esticar, fixar-romper, atender-desatender.

Sendo assim, pode-se pensar que a aprendizagem de um modo de atenção aberta à invenção, na sala de aula, requer, mais do que uma competência exigida para o exercício da docência; é uma questão de atuação, de um modo de experimentar o ato de ensinar e aprender. É, também, uma questão de qualidade da atenção posta em atuação na atividade pedagógica, que implica a possibilidade de descentração. Este modo de atuar se desenvolve desde uma concepção de aprendizagem enquanto processo, não seria possível se fosse

com o outro, e não para ele. Num diálogo estão implicadas ações como concordar, responder, perguntar, discordar, prestar atenção, respeitar o outro em sua diferença. de outro modo. Assim, pensa-se que tanto o modo de atender aos alunos quanto o modo de compreender a aprendizagem se constroem em sintonia uma com a outra. Trata-se de uma construção sempre inacabada.

\section{Considerações Finais}

Ao entendermos as práticas pedagógicas como uma experiência escolar dialógica interacional, que pressupõe experiências de encontro de saberes e de compartilhamento de experiências, seremos conduzidos a levantar a hipótese de que estas práticas exigem doses de atenção distintas daquelas que a maioria das crianças escolares experimentam hoje. Para que seja possível um enfrentamento com os contextos e práticas da vida diária, parece necessário o cultivo das duas possibilidades de atenção - a recognitiva e a inventiva - mas somente a última será capaz de produzir consciência e memória. Experiências rotineiras de acolhimento de breakdowns em sala de aula podem possibilitar o exercício de uma certa hegemonia da consciência sobre os apelos sensórios, tão empregados na contemporaneidade. Semeariam uma resistência ao excesso de focalização, em especial, aquela que inunda as salas de aula com estados de atenção tão desconectados e empobrecedores da disciplina criativa.

\section{Referências}

ARVIDSON, P.S. Bringing context into focus: parallels in the psychology on attention and the philosophy of science. Journal of Phenomenological Psychology, New York, v. 29, n. 1, p. 50-91, 1998

ARVIDSON, P.S. Transformations in consciousness: continuity, the self and marginal consciousness. Journal of Consciousness Studies, Exeter, v. 7, n. 3, p. 3-26, 2000.

BERGSON, Henri. Matéria e Memória: ensaio sobre a relação do corpo com o espírito. 2. ed. São Paulo: Martins Fontes, 1999.

BERGSON, Henri. A Evolução Criadora. São Paulo: Martins Fontes, 2005.

CRARY, J onathan. Suspensions of perception: attention, spectacle, and modern culture. Cambridge: MIT Press, 1999.

DE-NARDIN, Maria Helena. Um Estudo Sobre as Formas de Atenção na Sala de Aula e Suas Relações com a Aprendizagem. 2007. Dissertação (Mestrado) - Instituto de Psicologia, Universidade Federal do Rio Grande do Sul, 2007, Porto Alegre, BR-RS.

DE-NARDIN, Maria Helena; SORDI, Regina Orgler. Um Estudo Sobre as Formas de Atenção da Sala de Aula e 
Suas Implicações Para a Aprendizagem. Revista Psicologia \& Sociedade, Porto Alegre, v. 19, n. 1, p. 99-106, jan./abr. 2007.

DE-NARDIN, Maria Helena; SORDI, Regina Orgler. Aprendizagem da Atenção: uma abertura à invenção. Revista Semestral da Associação Brasileira de Psicologia Escolar e Educacional (ABRAPEE), Campinas, v. 13, n. 1, p. 97-106, jan./jun. 2009.

DEPRAZ, Natalie; VARELA, Francisco J.; VERMERSCH, Pierre. The gesture of awareness: an account of its structural dynamics. Amsterdam: John Benjamins Publ., 1999.

DEPRAZ, Natalie; VARELA, Francisco J.; VERMERSCH, Pierre. On becoming aware: a pragmatics of experiencing. Amsterdam: John Benjamins Publ., 2003.

FREUD, Sigmund. Recomendações aos Médicos que Exercem a Psicanálise. In: STRACHEY, A. (Org.) Obras Psicológicas Completas de Sigmund Freud. Ed. stander brasileira. Rio de Janeiro:Imago, 1969. V. 12.

JAMES, William. The Principles of Psychology. Great books of the western world. In: ENCYCLOPAEDIA Britannica. Cidade: editora, 1952. V. 53, p. 260-298.

KASTRUP, Virgínia. A Invenção de Si e do Mundo: uma introdução do tempo e do coletivo no estudo da cognição. Campinas, SP: Papirus, 1999.

KASTRUP, Virgínia. A Aprendizagem da Atenção na Cognição Inventiva. Revista Psicologia \& Sociedade, Porto Alegre, v. 16, n. 3, p. 7-16, set./dez. 2004.

VARELA, Francisco. O Reencantamento do Concreto. Cadernos de Subjetividade, São Paulo, v. s/n, n. s/n, p. 72-86, 2003.

VARELA, Francisco; THOMPSON, Evan; ROSCH, Eleanor. A Mente Incorporada: ciências cognitivas e experiência humana. Porto Alegre: Artmed, 2003.

Recebido em agosto de 2009

Aprovado para publicação em setembro de 2009

\section{Regina Orgler Sordi}

Professora adjunta do Instituto de Psicologia e do Programa de Pós-Graduação em Psicologia Social e Institucional da Universidade Federal do Rio Grande do Sul - email: sordi@vortex.ufrgs.br 